\title{
Development of a high sensitivity, nested Q-PCR assay for mouse and human aromatase
}

\author{
Gui-Jian Liu · Yu-sheen Wu · David Brenin · Wei Yue · Sarah Aiyar · \\ Anne Gompel · Ji-Ping Wang · Rajeshwar Rao Tekmal · Richard J. Santen
}

Published online: 4 December 2007

(C) Springer Science+Business Media, LLC. 2007

Erratum to: Breast Cancer Res Treat (2007)

DOI 10.1007/s10549-007-9792-4

There was an error in the first author's first name in the original article.

The online version of the original article can be found under doi:10.1007/s10549-007-9792-4.

G.-J.Liu - Y.Wu - D. Brenin - W. Yue - S. Aiyar - J.-P. Wang · R. J. Santen $(\bowtie)$

Departments of Internal Medicine and Surgery, University of Virginia, P.O. Box 801416, Charlottesville, VA 22908, USA

e-mail: RJS5Y@virginia.edu

A. Gompel

INSERM U673, Université Paris Descartes, APHP, Hôtel Dieu de Paris, Paris, France

R. R. Tekmal

Department of Obstetrics and Gynecology, University of Texas

Health Science Center at San Antonio, San Antonio, TX, USA

Present Address:

G.-J. Liu

Guang An Men Hospital, China Academy of Chinese Medical

Sciences, Beijing, China 